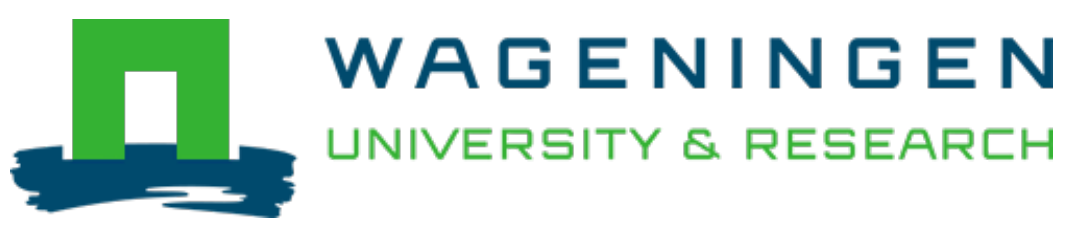

\title{
Stress gradients and biodiversity : monoculture vulnerability drives stronger biodiversity effects during drought years
}

\author{
Ecology \\ Wright, A.J.; Mommer, L.; Barry, K.; Ruijven, J. \\ https://doi.org/10.1002/ecy.3193
}

This article is made publicly available in the institutional repository of Wageningen University and Research, under the terms of article $25 \mathrm{fa}$ of the Dutch Copyright Act, also known as the Amendment Taverne. This has been done with explicit consent by the author.

Article 25 fa states that the author of a short scientific work funded either wholly or partially by Dutch public funds is entitled to make that work publicly available for no consideration following a reasonable period of time after the work was first published, provided that clear reference is made to the source of the first publication of the work.

This publication is distributed under The Association of Universities in the Netherlands (VSNU) 'Article $25 \mathrm{fa}$ implementation' project. In this project research outputs of researchers employed by Dutch Universities that comply with the legal requirements of Article $25 \mathrm{fa}$ of the Dutch Copyright Act are distributed online and free of cost or other barriers in institutional repositories. Research outputs are distributed six months after their first online publication in the original published version and with proper attribution to the source of the original publication.

You are permitted to download and use the publication for personal purposes. All rights remain with the author(s) and / or copyright owner(s) of this work. Any use of the publication or parts of it other than authorised under article $25 \mathrm{fa}$ of the Dutch Copyright act is prohibited. Wageningen University \& Research and the author(s) of this publication shall not be held responsible or liable for any damages resulting from your (re)use of this publication.

For questions regarding the public availability of this article please contact openscience.library@,wur.nl 


\title{
Stress gradients and biodiversity: monoculture vulnerability drives stronger biodiversity effects during drought years
}

\author{
A.J. Wright (D) ${ }^{1,5}$ L. Mommer, ${ }^{2}$ K. Barry (D) ${ }^{3,4}$ and J. vanRuiJVen ${ }^{2}$ \\ ${ }^{1}$ Department of Biological Sciences, California State University Los Angeles, 5151 State University Drive, Los Angeles, \\ California 90032 USA \\ ${ }^{2}$ Plant Ecology and Nature Conservation Group, Wageningen University, P.O. Box 47, Wageningen 6700 AA The Netherlands \\ ${ }^{3}$ Institute for Systematic Botany and Functional Biodiversity, Leipzig University, Johannisallee 21, Leipzig 04103 Germany \\ ${ }^{4}$ German Centre for Integrative Biodiversity Research, Deutscher Platz 5e, Leipzig 04103 Germany
}

Citation: Wright, A. J., L. Mommer, K. Barry, and J. van Ruijven. 2020. Stress gradients and biodiversity: monoculture vulnerability drives stronger biodiversity effects during drought years. Ecology 00(00):e03193. 10.1002/ecy.3193

\begin{abstract}
Climate change will increase the likelihood and severity of droughts into the future. Although diversity may buffer plant communities against the negative effects of drought, the mechanisms underlying this pattern remain unclear. Higher-diversity plant communities may have a higher likelihood of including more drought-resistant species that can compensate for drought-sensitive species ("insurance effects"). Alternatively, higher-diversity communities may alter environmental conditions and improve performance of even droughtsensitive species. Here we planted nonleguminous forbs and grasses into monocultures and four- and eight-species mixtures, and measured species and plot productivity every year from 2000 to 2010 . We found that six of our eight species were suppressed when growing in monoculture during dry years. These same species were unaffected by drought when growing in higherdiversity mixtures. Because of this poor performance in monoculture (not insurance effects), the biodiversity productivity relationship was strongest during the driest years. If biodiversity ameliorates hot/dry conditions and therefore improves performance of drought-sensitive species during periods of low rainfall, this may mean biodiversity can be used as a tool to protect individual species from drought conditions.
\end{abstract}

Key words: BEF; climate change; ecosystem function and services; microclimate amelioration; speciesspecific responses.

\section{INTRODUCTION}

Rapidly changing climatic conditions are increasing the global frequency and severity of extreme weather events such as drought (Trenberth 2011, Dai et al. 2018). Globally, the area of dry lands may increase by up to $10 \%$ by 2100 , because of both decreased precipitation and increased evapotranspiration with climate warming (Sherwood and Fu 2014). Regionally, severe drought risk may increase by up to $60 \%$ in some areas of Europe by 2100 , and growing-season soil moisture is projected to decrease by $2-3 \%$ in the next $20 \mathrm{yr}$ (Ruosteenoja et al. 2017).

Drought often negatively affects ecosystems: drought can decrease agricultural yields and ecosystem carbon sequestration (Ciais et al. 2005) and make ecosystems more vulnerable to subsequent disturbances (Niinemets 2010). However, biodiversity can buffer ecosystems against the loss of productivity and other ecosystem functions (Tilman and Downing 1994, Isbell et al. 2015;

Manuscript received 28 January 2020; revised 9 June 2020; accepted 6 August 2020. Corresponding Editor: Peter B. Adler.

${ }^{5}$ E-mail: awrigh20@calstatela.edu but see Pfisterer and Schmid 2002, Vogel et al. 2012, Craven et al. 2016). The ability of biodiversity to buffer ecosystems against stressful events is often considered a consequence of so-called "insurance effects"; higher-diversity ecosystems are more likely to contain species that are capable of persisting and sometimes thriving in severe environmental conditions; these species can then compensate for losses experienced by more vulnerable species (Yachi and Loreau 1999, Hector et al. 2010, Hautier et al. 2014). An assessment of the insurance hypothesis thus requires a comparison of species-specific responses to drought: some drought-sensitive species may perform poorly during a drought, regardless of the diversity or identity of the species around them. Some drought-tolerant species may perform well during a drought, and their enhanced performance during drought may compensate for the poor performance of drought-sensitive neighbors in higher-diversity plant communities.

Importantly, experimental results from the facilitation literature demonstrate that drought may also increase the importance and strength of direct interspecific facilitative interactions between plants (e.g., the stress gradient hypothesis, Bertness and Callaway 1994). In the 
context of biodiversity ecosystem functioning (BEF) research, the stress-gradient hypothesis predicts that drought-sensitive species may be buffered against climate extremes when growing in (1) higher-diversity or higher biomass plant communities, and (2) near drought-resistant neighbors (Caldeira et al. 2001, Wright et al. 2014, 2015). This is because higher-diversity communities can be more productive and thus provide greater shade, cooler air temperatures, increased relative humidity, increased likelihood of including deep-rooted species, and increased surface soil moisture at the community level (Wright et al. 2014, Steinauer et al. 2015, Cowles et al. 2016). These buffering effects can reduce water losses for drought-sensitive species (Wright et al. 2015), and this may allow individual drought-sensitive species to persist during drought, depending on the diversity and identity of their neighbors.

Furthermore, resource partitioning theory suggests that intraspecific competition should be greater than interspecific competition for many species (HilleRisLambers et al. 2012). Although conspecific neighbors likely compete for resources in overlapping ways, heterospecific neighbors may have complementary root distributions (but see Barry et al. 2020), alternative physiological strategies to combat water stress (Fotelli et al. 2000), or alternative energy allocation patterns that reduce water loss aboveground (e.g., lower specific leaf area of leaves). If intraspecific competition outweighs interspecific competition, this could buffer species from strong competition for soil water during drought.

If individual species are buffered from negative environmental conditions in higher-diversity communities (but not in lower-diversity communities, e.g., Fig. 1), this may also help explain how higher-diversity communities are protected from productivity losses during drought. This mechanism has not been given full attention in the biodiversity-stability literature thus far. Here, we use data from a 10-yr biodiversity experiment in Wageningen, the Netherlands to assess the following two hypotheses: (1) BEF relationships are stronger during periods of low rainfall and (2) stronger BEF relationships during periods of low rainfall are related to individual species performing better when growing near heterospecific neighbors than when growing near conspecific neighbors. This may be due to either interspecific facilitation or alleviation of intraspecific competition.

\section{Materials And Methods}

\section{Field experiment}

The Wageningen Biodiversity Experiment was established in 2000 and ended in 2010 at Wageningen University in The Netherlands (Van Ruijven and Berendse 2003, 2010, Van Ruijven et al. 2003). The experiment is characterized by a cool temperate climate with an average annual temperature of $10.2^{\circ} \pm 0.7^{\circ} \mathrm{C}$ and approximately $847.3 \mathrm{~mm}$ of rainfall annually (Bakker et al.
2016). The experiment was established using four grass species (Agrostis capillaris L., Anthoxanthum odoratum L., Festuca rubra L., and Holcus lanatus L.) and four forb species (Centaurea jacea L., Leucanthemum vulgare Lamk., Plantago lanceolata L., and Rumex acetosa L.). We planted 3-week-old seedlings into equally spaced 12 seedling $\times 12$ seedling grid cells within $1 \times 1 \mathrm{~m}$ plots (144 seedlings per plot). The plots were assigned to one of four diversity levels in six replicated blocks. Each block contained eight monocultures (one for each species), four mixtures of two and four species, and one eight-species mixture (17 plots per block and 102 total experimental plots). Species in two- and four-species plots were assigned randomly, such that the same twoor four-species mixtures were never replicated (in order to maximize the number of species combinations examined). All plots were watered regularly during the first 3 months of growth to ensure proper establishment. After this period, we stopped watering plots. Species composition of plots was maintained by hand weeding. All plots were surrounded with a buffer zone that was sown with a mixture of grass species that were not in the species pool used in our experiment. These walkways were mown regularly.

Plot biomass was measured annually by clipping all plant material to $2.5 \mathrm{~cm}$ above the soil surface in August of each year. Biomass was sorted to species, dried for at least $48 \mathrm{~h}$ at $70^{\circ} \mathrm{C}$, and weighed. To avoid edge effects, only the central $60 \times 60 \mathrm{~cm}$ of plot biomass were used for analyses.

\section{Rainfall measurements}

Precipitation data were obtained from the Haarweg meteorological station in Wageningen, located approximately $2 \mathrm{~km}$ from the experimental site (Tank et al. 2002). Precipitation was recorded in millimeters and summed per month over the course of the growing season (April-August) from 2000 to 2010. Average precipitation per month was then averaged for each growing season and used as a covariate in our analyses. Importantly, this 10 -yr period covered a wide range of rainfall conditions. This included the severe drought that occurred in Europe in July 2003, with temperatures up to $6^{\circ} \mathrm{C}$ greater than long-term averages and precipitation at $50 \%$ below the long-term average (Ciais et al. 2005). This also included the 2006 drought that was characterized by just $47 \mathrm{~mm}$ of precipitation from June to July 2006 (compared to a long-term average of $140 \mathrm{~mm}$ ) and had strong effects on plant growth in this experiment (Van Ruijven and Berendse 2010).

\section{Biomass/performance indices}

We assessed the strength of the BEF effect by comparing biomass per square meter $\left(\mathrm{g} / \mathrm{m}^{2}\right)$ in each diversity level in each year. To assess species-specific growth in a given year at a given level of plant diversity in 
comparison with long-term average growth (suppression or enhancement), we calculated: $\mathrm{VI}=B_{i j k}-\bar{B}_{i R}$ where VI is the vulnerability index, $B_{i j k}$ is the biomass of species $i$ in plot $j$ in year $k$, and $-B_{i R}$, is the average biomass of species $i$ for that $(R)$ richness level $(1,2,4$, or 8 species). Thus, we could assess how the performance of each individual species in a given plot in a given year (with a given amount of precipitation) deviated from how that species usually performed in that level of biodiversity. For example, a VI greater than 0 indicated that an individual species was growing better than average and a VI less than 0 indicated that the species was growing worse than average. We also calculated: $\mathrm{VI}_{\text {prop }}=B_{i j k} / \bar{B}_{i R}$ to assess proportional responses of individual species in comparison with their long-term average performance. $A \mathrm{VI}_{\text {prop }}$ greater than 1 indicated better than average performance, whereas a value between 0 and 1 indicated worse-than-average performance.

We used our absolute VI index to understand speciesspecific patterns underlying the standard BEF relationship. We used our proportional VI index to understand relative species-specific patterns underlying a proportional BEF relationship. In particular, we were interested in whether some species perform well regardless of the identity or diversity of their neighbors. We were also interested in whether some species grow proportionally more during drought and thus compensate for losses experienced by drought-sensitive neighbors. Finally, our species-specific metrics can assess whether some species are less sensitive to the drought depending on the identity and diversity of their neighbors.

\section{Statistical analyses}

We assessed how the absolute and proportional BEF relationship changed as a function of annual precipitation using a mixed-effects model that included plot biomass (or proportional biomass) as the response variable, continuous fixed effects for year of study, species richness, annual precipitation (April-August), and the interaction between species richness and precipitation. We also included a random effect for plot nested in block to account for repeated measurements of the same plots over time and the blocked spatial layout of the experiment. We also included a random effect for year of study (discrete variable) to account for random variation in performance of plots from year to year (each year has its own y-intercept) that is not associated with precipitation or continuous changes in performance over (PlotBiomass $\sim \mathrm{Sp} \quad$ Rich $\times$ Precipitation + year, random $=$ Block/plot, random = year, e.g., Davidson et al. 1984). We also tested several other slightly more complicated error covariance structures (plot and block nested in year vs. plot nested in year and plot nested in block) and chose this error structure because it yielded the lowest Akaike information criterion $\left(\mathrm{AIC}_{\mathrm{c}}\right)$ scores. Finally, we also analyzed all of our results using a Type III ANOVA design (main results reported here are Type II ANOVA,
Type III ANOVA results in Appendix S1: Table S1). There is an ongoing debate in the statistical community about which approach is more appropriate for unbalanced data, thus we report on both here (Langsrud 2003). Importantly, the two approaches do not affect the interactions that we are concerned with for the purposes of this study.

We also binned the precipitation measurements into three groups: low (51-57 $\mathrm{mm}$ rainfall), medium (61-74 $\mathrm{mm}$ rainfall), and high (76-92 $\mathrm{mm}$ rainfall). We used these three groups as this allowed for a near-equal sample size within each binned category $(n=4 \mathrm{yr}$ in low rainfall and medium rainfall, $n=3 \mathrm{yr}$ in the high rainfall group). We also included species richness as a categorical variable in this model to be able to use post hoc Tukey tests to compare between all binned groups (e.g., monocultures in rainy years vs. high-diversity plots in dry years) and to determine whether differences in $\mathrm{BEF}$ relationships were due to monoculture suppression during periods of low rainfall or due to higher diversity enhancement during periods of high rainfall. All other aspects of the model structure for this analysis were identical to the model described above. Overall results from this analysis were not different from the continuous variable model, and thus we just report on the results from the Tukey tests here.

To assess how individual species biomass was enhanced or suppressed by annual precipitation (continuous) and modified by community diversity (continuous), we used a mixed effects model with VI (or $\mathrm{VI}_{\text {prop}}$ ) as the response variable, continuous fixed effects for year of study, species richness, annual precipitation (April to August), the interaction between species richness and precipitation, and a random effect for year and plot nested within block (VI $\sim$ Sp Rich $\times$ Precipitation, random $=$ Block $/$ plot, random $=$ year $)$.

\section{RESULTS}

Ambient precipitation at the site ranged from $51 \mathrm{~mm}$ per month during the 2010 growing season to $91 \mathrm{~mm}$ per month during the 2007 growing season with no significant correlation between time and growing-season precipitation (Fig. 2, $R=-0.31$ ). Growing season precipitation did not have a strong overall effect on biomass production $\left(\chi_{1,9}^{2}=3.24, P=0.07\right.$, Table 1$)$. Year of study had a significant negative effect on overall biomass production $\left(\chi_{1,9}^{2}=8.13, P=0.0004\right.$, Table 1$)$ indicating reduced performance over time. Year of study also had a significant negative effect on biomass production of Festuca rubra, Holcus lanatus, Plantago lanceolata, and Rumex acetosa (Table 2).

We found that the strength of the BEF relationship increased during drier years (51-57 mm precipitation class, SR $\times$ precipitation interaction, Table 1, Fig. 3a), and this corresponded with lower monoculture performance in the drier years paired with no significant changes in higher diversity mixture performance in any 


\section{(a) Monoculture}

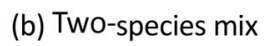

(c) Four-species mix

(d) Eight-species mix
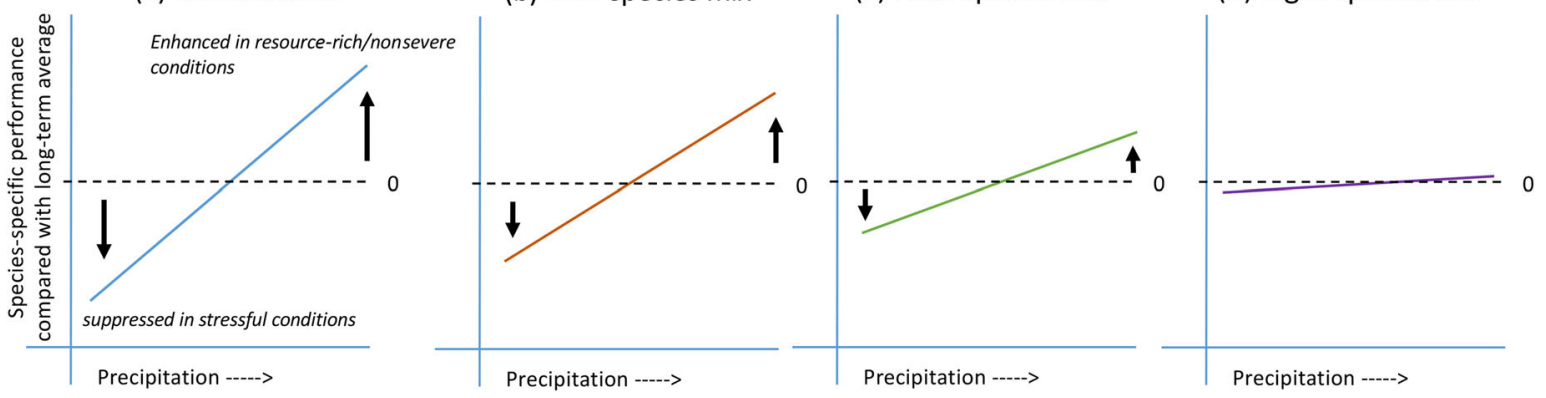

FIG. 1. Conceptual model of the monoculture vulnerability hypothesis. Some drought-sensitive species may be strongly suppressed when growing alone in monoculture during dry years (a). These same species may thrive in monoculture during wet years (a). If biodiversity provides some kind of buffer against fluctuations in precipitation (drought conditions), these same species should not respond strongly to fluctuations in precipitation when they are growing in higher-diversity mixtures (b-d).

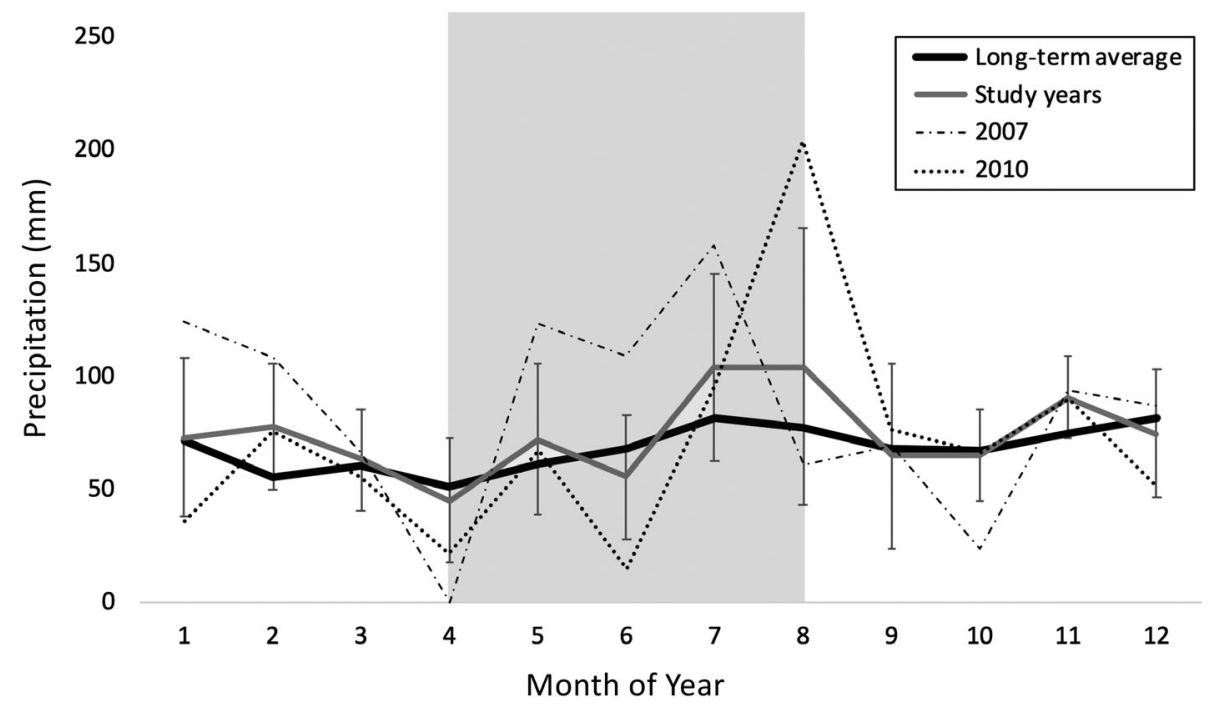

FIG. 2. Precipitation patterns over the course of this study in comparison with the long-term average (1951-2012). The data presented here cover the 2000-2010 growing season (April-August, shaded gray). The study years were overlapping with long-term average trends. The wettest year of the study was 2007, and the driest year of the study was 2010 .

years (Fig. 3a). We also found that rainfall strongly affected our proportional community biomass measures. When we compared annual proportional biomass production in each plot with long-term averages, we found that monocultures grew $25 \%$ less than average during dry years and $30 \%$ greater than average during wet years $(\mathrm{SR} \times$ precipitation interaction, Table 1, Fig. $3 b)$. Higher-diversity mixtures did not grow more or less than average in wet or dry years (Fig. 3b).

In terms of species-specific changes in growth (VI index), we found that six out of the eight species performed poorly when growing in monoculture during dry years but not wet years (Agrostis capillaris, Anthoxanthum odoratum, Festuca rubra, Holcus lanatus, Leucanthemum vulgare, and Plantago lanceolata). The first year of the experiment was also the second wettest year of the experiment, and thus these species were likely affected by both precipitation effects and increased performance in monoculture in their first year (Fig. 4). However, even after accounting for the effects of time in our statistical model, there was still an interaction between precipitation and the species richness of the plot. In other words, these species were unaffected by precipitation when growing in higher-diversity mixtures but strongly affected by precipitation when growing alone in monoculture $(\mathrm{SR} \times$ precipitation interactions, Table 2, Fig. 4). The other two species (Rumex acetosa and Centaurea jacea) were not directly affected by precipitation in any of the diversity mixtures.

In terms of proportional growth responses $\left(\mathrm{VI}_{\text {prop }}\right)$, we found that two of these species were negatively affected by drought when growing in monoculture but not when growing in mixture (similar to absolute VI analyses). We found that one species (Holcus lanatus) 
TABLE 1. We used a mixed-effects model to assess the role of year of the study (Year), planted species richness (Sp Richness), precipitation during the growing season (April-August) and the interaction between species richness and precipitation on biomass production in our plots.

\begin{tabular}{|c|c|c|c|c|c|c|c|c|c|c|}
\hline \multirow[b]{2}{*}{ Factor } & \multicolumn{5}{|c|}{ Absolute BEF } & \multicolumn{5}{|c|}{ Proportional BEF } \\
\hline & Estimate & $\begin{array}{l}\text { Standard } \\
\text { error }\end{array}$ & df & ChiSq & $P$ value & Estimate & $\begin{array}{l}\text { Standard } \\
\text { error }\end{array}$ & $\mathrm{df}$ & ChiSq & $P$ value \\
\hline Year & -8.83 & 3.10 & 1,9 & 8.13 & $0.004^{*}$ & -0.06 & 0.02 & 1,9 & 9.48 & $0.002^{*}$ \\
\hline Species richness & 36.1 & 7.11 & 1,100 & 32.0 & $<0.0001^{*}$ & 0.16 & 0.04 & 1,100 & 0.00 & 1.000 \\
\hline Precipitation & 1.96 & 0.81 & 1,9 & 3.24 & 0.07 & 0.01 & 0.005 & 1,9 & 3.24 & 0.07 \\
\hline $\begin{array}{l}\text { Species richness } \times \\
\text { precipitation }\end{array}$ & -0.24 & 0.09 & 1,1009 & 6.73 & $0.0095^{*}$ & -0.002 & 0.0005 & 1,1009 & 19.7 & $<0.0001^{*}$ \\
\hline
\end{tabular}

Notes: We included a random effect for plot nested within block to account for repeated measurements taken over time and spatial autocorrelation of measurements taken within closer proximity to one another at the field site (blocked design). We also included a random effect for year of study to account for random year-to-year variation in the plots that is not associated with precipitation or continuous change over time. Significant results are marked with an asterisk.

TABLE 2. We used a mixed-effects model to assess the role of year of the study (Year), planted species richness (Sp Richness) and precipitation during the growing season (April-August) and the interaction between species richness and precipitation on vulnerability index for each individual species in our plots.

\begin{tabular}{|c|c|c|c|c|c|c|c|c|c|c|c|c|}
\hline & \multicolumn{3}{|c|}{ Year } & \multicolumn{3}{|c|}{ Species richness } & \multicolumn{3}{|c|}{ Precipitation } & \multicolumn{3}{|c|}{$\begin{array}{c}\text { Species richness } \times \\
\text { precipitation }\end{array}$} \\
\hline & df & ChiSq & $P$ value & df & ChiSq & $\begin{array}{c}P \\
\text { value }\end{array}$ & $\mathrm{df}$ & ChiSq & $\begin{array}{c}P \\
\text { value }\end{array}$ & $\mathrm{df}$ & ChiSq & $P$ value \\
\hline $\begin{array}{l}\text { Agrostis } \\
\text { capillaris }\end{array}$ & 1,9 & 1.97 & 0.16 & 1,28 & 0.00 & 1.00 & 1,9 & 5.89 & $0.02 *$ & 1,289 & 49.4 & $<0.0001^{*}$ \\
\hline $\begin{array}{l}\text { Anthoxanthum } \\
\text { odoratum }\end{array}$ & 1,9 & 2.71 & 0.10 & 1,27 & 0.00 & 1.00 & 1,9 & 9.93 & $0.002^{*}$ & 1,279 & 9.55 & $0.002^{*}$ \\
\hline $\begin{array}{l}\text { Centaurea } \\
\text { jacea }\end{array}$ & 1,9 & 0.46 & 0.50 & 1,28 & 0.00 & 1.00 & 1,9 & 0.57 & 0.45 & 1,289 & 0.78 & 0.38 \\
\hline Festuca rubra & 1,9 & 12.7 & $0.0003^{*}$ & 1,29 & 0.00 & 1.00 & 1,9 & 3.44 & 0.06 & 1,299 & 20.5 & $<0.0001^{*}$ \\
\hline Holcus lanatus & 1,9 & 4.63 & $0.03^{*}$ & 1,28 & 0.00 & 1.00 & 1,9 & 2.48 & 0.12 & 1,289 & 33.5 & $<0.0001^{*}$ \\
\hline $\begin{array}{l}\text { Leocanthemum } \\
\text { vulgare }\end{array}$ & 1,9 & 0.10 & 0.32 & 1,28 & 0.00 & 1.00 & 1,9 & 0.17 & 0.68 & 1,289 & 18.7 & $<0.0001^{*}$ \\
\hline $\begin{array}{l}\text { Plantago } \\
\text { lanceolata }\end{array}$ & 1,9 & 11.7 & $0.0006 . *$ & 1,28 & 0.00 & 1.00 & 1,9 & 4.18 & $0.04^{*}$ & 1,289 & 29.1 & $<0.0001^{*}$ \\
\hline Rumex acetosa & 1,9 & 25.3 & $<0.0001^{*}$ & 1,28 & 0.00 & 1.00 & 1,9 & 8.19 & $0.004^{*}$ & 1,289 & 0.14 & 0.70 \\
\hline
\end{tabular}

Notes: Vulnerability index was assessed as biomass production in a given year in comparison with average annual biomass production for that species. We included a random effect for plot nested within block to account for repeated measurements in the same plots over time, autocorrelation of multiple measurements taken on different species within a single plot at each sampling point, and the spatially nested nature of plots within larger blocks at our field site. We also included a random effect for random year-toyear variation in the plots that is not associated with precipitation or continuous change over time. Because our index is normalized to each species richness level, we (a priori) expect a perfect fit for each species as a function of species richness. Interactions between species richness and precipitation indicate biologically meaningful results. Significant results are marked with an asterisk.

grew proportionally more in high-rainfall years, but more strongly in higher-diversity plots (indicating compensation for other species that may have been affected negatively), and we found that one species (Centaurea jacea) grew proportionally more in drought years, but mostly just in higher-diversity plots (Appendix S1: Table S2 and Fig. S1).

\section{Discussion}

Here we confirm past results that higher-diversity communities can better resist productivity changes caused by drought (Isbell et al. 2015). Importantly, we also demonstrate, for the first time, that this can be driven by a buffering of drought-sensitive species responses when these species are grown in higher-diversity mixtures. Specifically, we found that six of our eight grassland species were sensitive to annual precipitation, but only when growing in monoculture. These same individual species, when growing in higher-diversity mixtures, during these same dry years, were unaffected by annual changes in precipitation. This may be due to alleviation of intraspecific competition. This result is also consistent with past evidence that diversity may moderate environmental conditions and make the microclimate more hospitable for sensitive species (Caldeira et al. 2001, Wright et al. 2015, 2017, Barry et al. 2018). We call this the "monoculture 


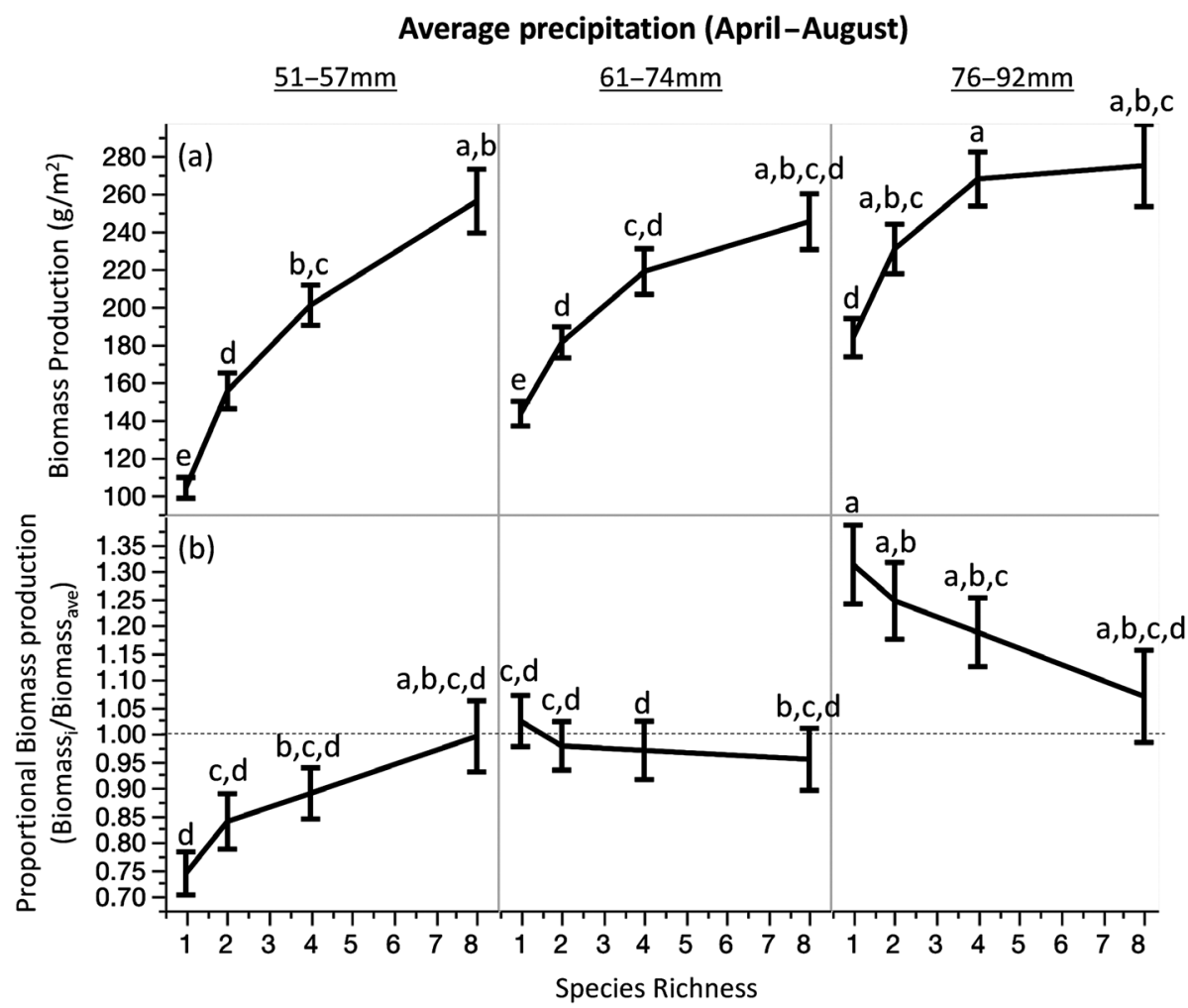

FIG. 3. We assessed the effects of species richness on biomass production every year from 2000 to 2010 . We also assessed how species richness and precipitation affected proportional biomass production in year $i$ compared with average biomass production for that species richness level across all $11 \mathrm{yr}$ of the experiment. The strength of the effect of species richness on biomass production was strongest in dry years (51-61 mm rainfall). Proportional biomass productions was also strongly affected by growing-season precipitation. Error bars represent standard error of the mean. Letters indicate significant differences according to post hoc Tukey tests to assess multiple comparisons between species diversity levels at different levels of precipitation.

vulnerability hypothesis"; some species are sensitive to drought conditions when growing in monoculture but are buffered from these negative effects when growing in higher-diversity mixtures.

\section{BEF relationships are stronger during periods of low rainfall}

Climate change is expected to increase the severity and frequency of drought in the future, and past work has demonstrated that biodiversity may be used as a tool to mitigate some of the most negative effects of drought. However, the majority of past work on the role of biodiversity during drought has focused on insurance effects: higher-diversity communities are more likely to resist drought at the community level because of a higher likelihood of containing drought-resistant species (Naeem and Li 1997). In other words, drought-resistant species can compensate at the community level for drought-sensitive species in higher-diversity mixtures (Hector et al. 2010). These so-called insurance effects have been suggested to lead, at least partially, to the maintenance of biomass production in mixtures during drought, but average monoculture productivity declines (Tilman and Downing 1994, Isbell et al. 2015).
A recent meta-analysis by Isbell et al. (2015) demonstrated consistent patterns in ecosystem responses to natural drought across 46 different experiments: higherbiodiversity plant communities were more resistant to changes in biomass production during drought conditions. Further, during moderate drought (drought events occurring between once every 4 yr or once per decade), monocultures were suppressed strongly during the drought, whereas higher-diversity mixtures maintained normal levels of biomass production (Isbell et al. 2015). Our findings provide additional mechanistic insight by focusing on individual species: individual species were sensitive to drought conditions when growing in monoculture, but these same species were insensitive to the drought when growing in higher-diversity mixtures.

Interestingly, these results differ from past assessments of drought effects during experimental drought manipulations (e.g., rainfall exclusion). In fact, a recent meta-analysis of experimental drought demonstrated that higher-diversity communities responded more negatively to experimental drought than lowerdiversity communities (Craven et al. 2016). It is thus far unclear why drought responses differ between experimental manipulations (Craven et al. 2016) and natural variation in drought conditions (Isbell et al. 


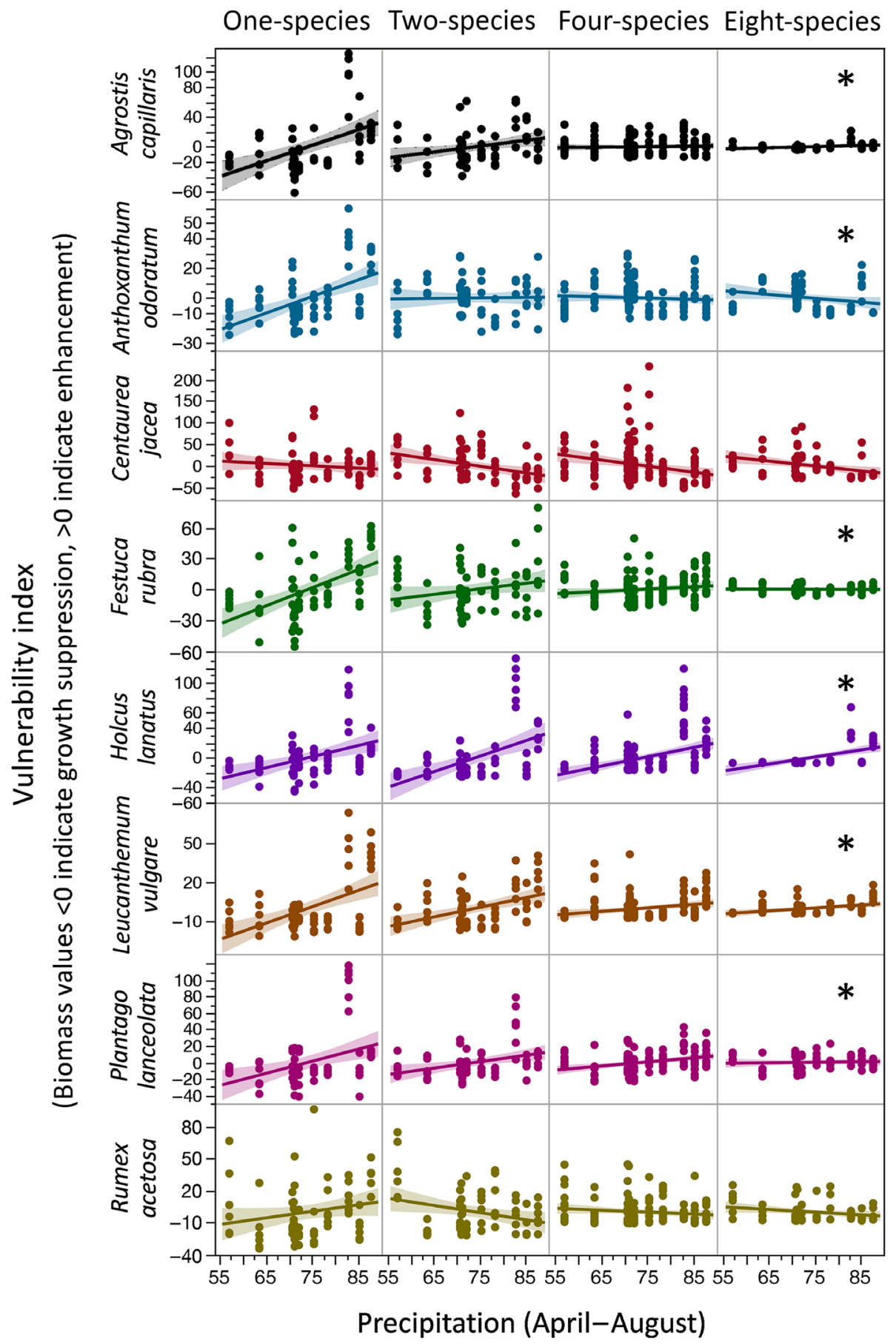

FIG. 4. We measured the vulnerability index for each species in each year of the experiment by comparing species-specific biomass production in that year and compared it with average biomass production for that species over time. We found a significant interaction between growing-season precipitation and species richness of the plot for six of eight species: Agrostis capillaris, Anthoxanthum odoratum, Festuca rubra, Holcus lanatus, Leucanthemum vulgare, and Plantago lanceolata (indicated with an asterisk). Shaded regions indicate $95 \%$ confidence intervals.

2015). One possibility that is relevant for the current study is a difference in how drought is applied between experimental droughts (rainfall is removed) vs. natural droughts (rainfall is reduced AND evaporative demand is increased). Future work should assess these facilitation indices in response to experimental manipulations of drought via careful manipulation of soil moisture and increased evaporative 
demand (see Vicca et al. 2012 and Kreyling et al. 2017 for discussion of associated issues).

\section{Insurance effects}

One forb species (Centaurea jacea) in our analysis appears to be compensating slightly for relative losses experienced by drought-sensitive species in higher-diversity plots during dry years. In drought years, this species grew approximately 1.5 times more than it did in an average year. However, insurance effects do not appear to be the main driver of the maintenance of high productivity over time in higher-diversity plots (only one of eight species showed such a pattern). Furthermore, if insurance effects drove the sustained biomass production of high-diversity communities during drought, we would expect to see decreased biomass production in drought-sensitive species at all diversity levels. We did not observe this effect, suggesting alternative mechanisms underlie our results.

\section{Facilitation and alleviation of competition in higher- diversity mixtures}

Six of our eight species performed poorly when growing in monoculture during dry years but not wet years (Agrostis capillaris, Anthoxanthum odoratum, Festuca rubra, Holcus lanatus, Leucanthemum vulgare, and Plantago lanceolata). These same species were unaffected by drought when growing in higher-diversity mixtures (in terms of absolute biomass production). Both Leucanthemum vulgare and Plantago lanceolata followed these same patterns when assessed in terms of proportional biomass production. Cong et al. (2014) demonstrated that these same six species have proportionally more root biomass in the shallowest root horizon in comparison with the two species that did not follow these trends (Centaurea jacea L., and Rumex acetosa L.). Shallow rooting depth may be one of several factors contributing to drought sensitivity of these six species. Past work at a temperate North American grassland has shown that higher-diversity microclimates are cooler and more humid, and have lower vapor pressure deficit and higher surface level soil moisture than lower-diversity communities (Wright et al. 2015, Cowles et al. 2016). This has been shown to lead to decreased mortality for some species (Wright et al. 2013), reduced water stress during periods of drought (Caldeira et al. 2001, Wright et al. 2014), and increased growth of sensitive species growing in higher-diversity mixtures during periods of drought (Wright et al. 2015). These known changes in microclimate conditions in higher-diversity communities, paired with our data on species-specific responses to drought in higher-diversity communities, indicate the important role that biodiversity-microclimate effects may play in explaining stronger BEF relationships during dry years.

Although strong interspecific facilitation may help explain these results, alleviation of strong intraspecific competition could also result in similar patterns. Lowerdiversity communities may experience greater competition for soil water during dry years. If intraspecific competition for soil moisture outweighs interspecific competition during these dry periods (e.g., niche complementarity effects, HilleRisLambers et al. 2012), individual species may experience alleviation of intense intraspecific competition when growing in higher-diversity plots. Although we cannot rule this out as a contributing mechanism, a recent meta-analysis by Barry et al. (2020) found that spatial resource partitioning for belowground resources is quite rare in 21 experimental manipulations of grassland biodiversity around the world. Although competition for soil moisture is inevitably occurring, it is likely paired with well-known aboveground effects of diversity on evaporative demand. Higher-diversity communities offer both alleviation of intense intraspecific competitions, and unique microclimatic conditions that reduce water losses.

Finally, monoculture suppression has been demonstrated in BEF research in the past, but this work has mainly focused on the suppressive role of species-specific pests and pathogens (Hendriks et al. 2013). Speciesspecific pests and pathogens accumulate in monocultures over time and suppress monoculture performance. These density-dependent effects are diluted in higher-diversity mixtures, where herbivory by species-specific pests and pathogens is reduced (Mommer et al. 2018). Although this type of monoculture suppression may also be occurring in our experiment, we would not expect it to increase in drought years when pathogen densities are likely relatively low (unless low pathogen load is paired with disproportionately high pathogen sensitivity). We would also expect this effect to be more tightly tied to increased pathogen suppression over time, as opposed to peaks in suppression tied to particular years.

\section{Conclusion and Future Perspectives}

Recent work has found consensus that higher-diversity plant communities resist against biomass losses during moderate natural droughts (Isbell et al. 2015). Although the vast majority of past studies have pointed at the importance of insurance effects to explain these biodiversity patterns, we present clear evidence that protection of even drought-sensitive species may also underlie these results. This is an important distinction to make. Whereas insurance effects emphasize the probability of including drought-resistant species in mixture, our results are less reliant on drought-resistant species and point to the emergent properties of biodiversity in higher-diversity mixtures. In fact, higher-diversity mixtures can protect even drought-sensitive species from the negative effects of drought. The theoretical and management distinctions between these two mechanisms are important. For example, if abiotic facilitation is responsible for biodiversity-stability patterns during droughts, biodiversity may be one method by which to maintain 
populations of sensitive or rare species in the face of climate change. Furthermore, insurance effects and facilitation are likely driven by different environmental factors. For example, although insurance effects may not be directly related to evaporative demand, facilitation is stronger and more important when evaporative demand increases (via microclimate amelioration, Wright et al. 2015). Future experiments that manipulate the role of biodiversity during drought should be careful to assess all aspects of drought in order to capture the multiple mechanisms that likely underlie the ability of biodiversity to buffer ecosystems against drought.

\section{ACKNOWLEDGMEnTS}

We are grateful to Frans Möller, Jan van Walsem, Maurits Gleichman, and numerous other field workers who helped maintaining the experiment and collecting the data. AJW acknowledges startup funds from California State University Los Angeles that helped with completion of this manuscript. The establishment of the Wageningen Biodiversity Experiment was supported by a grant from the Dutch Organisation for Scientific Research (NWO) within the framework of the Biodiversity Programme. LM is supported by NWO-VIDI grant $864.14 .006 . \mathrm{KB}$ is supported by the German Centre for Integrative Biodiversity Research Halle-Jena-Leipzig's Flexpool project 34600900. Statement of authorship: AJW proposed the framework, ran the analyses, and wrote the first draft of the manuscript. JvR proposed the original experiment and LM and JvR collected the data. All coauthors contributed to analyses and contributed substantially to revisions of the manuscript.

\section{Literature Cited}

Bakker, L., L. Mommer, and J. Ruijven. 2016. Can root trait diversity explain complementarity effects in a grassland biodiversity experiment? Journal of Plant Ecology. https://doi. org/10.1093/jpe/rtw111

Barry, K. E., et al. 2018. The future of complementarity: disentangling causes from consequences. Trends in Ecology \& Evolution 34:1-14.

Barry, K., et al. 2020. Limited evidence for spatial resource partitioning across temperate grassland biodiversity experiments. Ecology 101:e0295.

Bertness, M., and R. Callaway. 1994. Positive interactions in communities. Trends in Ecology \& Evolution 9:191-193.

Caldeira, M. C., R. J. Ryel, J. H. Lawton, and J. S. Pereira. 2001. Mechanisms of positive biodiversity-production relationships: insights provided by $\delta^{13} \mathrm{C}$ analysis in experimental Mediterranean grassland plots. Ecology Letters 4:439-443.

Ciais, P., et al. 2005. Europe-wide reduction in primary productivity caused by the heat and drought in 2003. Nature 437:529-533.

Cong, W.-F., J. Van Ruijven, L. Mommer, G. B. De Deyn, F. Berendse, and E. Hoffland. 2014. Plant species richness promotes soil carbon and nitrogen stocks in grasslands without legumes. Journal of Ecology 102:1163-1170.

Cowles, J. M., P. D. Wragg, A. J. Wright, J. S. Powers, and D. Tilman. 2016. Shifting grassland plant community structure drives positive interactive effects of warming and diversity on aboveground net primary productivity. Global Change Biology 22:741-749.

Craven, D., et al. 2016. Plant diversity effects on grassland productivity are robust to both nutrient enrichment and drought.
Philosophical Transactions of the Royal Society B 371:20150277-20150278.

Dai, A., T. Zhao, and J. Chen. 2018. Climate change and drought: a precipitation and evaporation perspective. Current Climate Change Reports 4:301-312.

Davidson, D. W., R. S. Inouye, and J. H. Brown. 1984. Granivory in a desert ecosystem: experimental evidence for indirect facilitation of ants by rodents. Ecology 65:1780-1786.

Fotelli, M., K. Radoglou, and H. Constantinidou. 2000. Water stress responses of seedlings of four Mediterranean oak species. Tree Physiology 20:1065.

Hautier, Y., et al. 2014. Eutrophication weakens stabilizing effects of diversity in natural grasslands. Nature 508:521-525.

Hector, A., et al. 2010. General stabilizing effects of plant diversity on grassland productivity through population asynchrony and overyielding. Ecology 91:2213-2220.

Hendriks, M., L. Mommer, H. de Caluwe, A. E. Smit-Tiekstra, W. H. Van Der Putten, and H. de Kroon. 2013. Independent variations of plant and soil mixtures reveal soil feedback effects on plant community overyielding. Journal of Ecology 101:287-297.

HilleRisLambers, J., P. B. Adler, W. S. Harpole, J. M. Levine, and M. M. Mayfield. 2012. Rethinking community assembly through the lens of coexistence theory. Ecology, Evolution, and Systematics 43:227-248.

Isbell, F., et al. 2015. Biodiversity increases the resistance of ecosystem productivity to climate extremes. Nature 526:574-577.

Kreyling, J., M. A. S. A. Khan, F. Sultana, W. Babel, C. Beierkuhnlein, T. Foken, J. Walter, and A. Jentsch. 2017. Drought effects in climate change manipulation experiments: quantifying the influence of ambient weather conditions and rain-out shelter artifacts. Ecosystems 20:301-315.

Langsrud, Ä. 2003. ANOVA for unbalanced data: use Type II instead of Type III sums of squares. Statistics and Computing 13:163-167.

Mommer, L., et al. 2018. Lost in diversity: the interactions between soil-borne fungi, biodiversity and plant productivity. New Phytologist 218:542-553.

Naeem, S., and S. Li. 1997. Biodiversity enhances ecosystem reliability. Nature 390:507-509.

Niinemets, Ã. 2010. Responses of forest trees to single and multiple environmental stresses from seedlings to mature plants: Past stress history, stress interactions, tolerance and acclimation. Forest Ecology and Management 260:1623-1639.

Pfisterer, A. B., and B. Schmid. 2002. Diversity-dependent production can decrease the stability of ecosystem functioning. Nature 416:84-86.

Ruosteenoja, K., T. Markkanen, A. Venäläinen, P. Räisänen, and H. Peltola. 2017. Seasonal soil moisture and drought occurrence in Europe in CMIP5 projections for the 21st century. Climate Dynamics 50:1177-1192.

Sherwood, S., and Q. Fu. 2014. A drier future? Science 343:737-739.

Steinauer, K., D. Tilman, P. D. Wragg, S. Cesarz, J. M. Cowles, K. Pritsch, P. B. Reich, W. W. Weisser, and N. Eisenhauer. 2015. Plant diversity effects on soil microbial functions and enzymes are stronger than warming in a grassland experiment. Ecology 96:99-112.

Tank, A. M. G. K., et al. 2002. Daily dataset of 20th-century surface air temperature and precipitation series for the European Climate Assessment. International Journal of Climatology 22:1441-1453.

Tilman, D., and J. A. Downing. 1994. Biodiversity and stability in grasslands. Nature 367:363-365.

Trenberth, K. E. 2011. Changes in precipitation with climate change. Climate Research 47:123-138. 
Van Ruijven, J., and F. Berendse. 2003. Positive effects of plant species diversity on productivity in the absence of legumes. Ecology Letters 6:170-175.

Van Ruijven, J., and F. Berendse. 2010. Diversity enhances community recovery, but not resistance, after drought. Journal of Ecology 98:81-86.

Van Ruijven, J., G. B. De Deyn, and F. Berendse. 2003. Diversity reduces invasibility in experimental plant communities: the role of plant species. Ecology Letters 6:910-918.

Vicca, S., et al. 2012. Urgent need for a common metric to make precipitation manipulation experiments comparable. New Phytologist 195:518-522.

Vogel, A., M. Scherer-Lorenzen, and A. Weigelt. 2012. Grassland resistance and resilience after drought depends on management intensity and species richness. PLoS One 7:e36992.

Wright, A., S. A. Schnitzer, I. A. Dickie, A. R. Gunderson, G A. Pinter, S. A. Mangan, and P. B. Reich. 2013. Complex facilitation and competition in a temperate grassland: loss of plant diversity and elevated $\mathrm{CO}_{2}$ have divergent and opposite effects on oak establishment. Oecologia 171:449-458.

Wright, A., S. A. Schnitzer, and P. B. Reich. 2014. Living close to your neighbors - the importance of both competition and facilitation in plant communities. Ecology 95:2213-2223.

Wright, A., S. A. Schnitzer, and P. B. Reich. 2015. Daily environmental conditions determine the competition-facilitation balance for plant water status. Journal of Ecology 103:648-656

Wright, A. J., D. A. Wardle, R. Callaway, and A. Gaxiola. 2017. The overlooked role of facilitation in biodiversity experiments. Trends in Ecology \& Evolution 32:383-390.

Yachi, S., and M. Loreau. 1999. Biodiversity and ecosystem productivity in a fluctuating environment: the insurance hypothesis. Proceedings of the National Academy of Sciences of the United States of America 96:1463-1468.

\section{SUPPORTING INFORMATION}

Additional supporting information may be found in the online version of this article at http://onlinelibrary.wiley.com/doi/ 10.1002/ecy.3193/suppinfo 